\title{
A GERAÇÃO Z E AS PLATAFORMAS TECNOLÓGICAS
}

\section{LA GENERACIÓN Z Y LAS PLATAFORMAS TECNOLÓGICAS}

\author{
Elismar Vicente Reis* \\ Maria Inês Tomaél**
}

\begin{abstract}
RESUMO:
Introdução: O crescimento exponencial da área de informática, do processamento e distribuição da informação possibilita aos integrantes da Geração Z o acesso a um vasto universo de informações sobre diversos assuntos. Objetivo: Verificar a participação da Geração Z nas plataformas tecnológicas, realizado com alunos do $3^{\circ} \mathrm{e}$ $4^{\circ}$ anos de uma escola federal de ensino médio no norte do Paraná. Metodologia: Análise de Redes Sociais (ARS), que possibilitou verificar o nível de interação e compartilhamento de informação por meio de dispositivos tecnológicos, e a técnica de Grupo Focal (GF), feita por temas e categorias, embasada na análise de conteúdo. Resultados: $O$ ato de permanecer online favorece a sensação de proximidade com outros indivíduos, fator considerado importante no acesso à informação e na possibilidade de atualização imediata dos acontecimentos. Por manterem o hábito de utilização de tecnologia, a Geração Z está acostumada a contatos constantes, acesso fácil e rápido a informação, e por isso sentiriam dificuldade em se desfazer de plataformas como smartphones. Conclusões: As condutas frente às plataformas tecnológicas são vistas mais como ações cotidianas do que como hábitos essenciais, embora identifiquem que a falta da tecnologia pode privá-los de oportunidades. Mesmo habituados aos processos tecnológicos de comunicação e informação, o grupo aqui pesquisado não considera que nasceu junto com a tecnologia, mas foram se adaptando a ela.
\end{abstract}

Palavras-chave: Compartilhamento da Informação. Dispositivo móvel. Análise de Redes Sociais. Redes Sociais.

\footnotetext{
*Mestre em Ciência da Informação pelo Programa de Pós-Graduação em Ciência da Informação da Universidade Estadual de Londrina (UEL). E-mail: elismarreis@bol.com.br

*Doutora em Ciência da Informação pelo Programa de Pós-Graduação em Ciência da Informação da Universidade Federal de Minas Gerais (UFMG). Docente do Programa de Pós-Graduação em Ciência da Informação da Universidade Estadual de Londrina (UEL). E-mail: mitomael@uel.br
}

Inf. Inf., Londrina, v. 22, n. 2, p. 371 - 388, maio/ago., 2017. http:www.uel.br/revistas/informacao/ 


\section{INTRODUÇÃO}

O pressuposto deste trabalho surgiu de observações das constantes mutações dos dispositivos tecnológicos de comunicação, além da percepção empírica de que os indivíduos acompanham essas mudanças e migram entre as diversas plataformas. Nos últimos anos temos assistido ao crescimento exorbitante das interações nos ambientes virtuais e o surgimento de aparatos tecnológicos cada vez mais acessíveis, uma junção que tem mudado a forma como as pessoas se comunicam e compartilham informação.

Em meio às inovações e hibridização das tecnologias disponíveis, nascem sujeitos já inseridos nos caminhos e velocidade da internet, aos jogos compartilhados online, conhecida como geração da era do conhecimento e denominados nativos digitais. Os nativos digitais compreendem pessoas que nasceram nas últimas décadas do século vinte (PRENSKY, 2001) e agregam as gerações $Y^{1}$ e $Z$.

Embora classificadas pelo ano de nascimento, não há consenso para o intervalo de datas em relação a cada geração na atualidade. Cerbasi e Barbosa (2009), por exemplo, definem que a Geração $Z$ agrupa sujeitos nascidos após o ano 2000; para Fernandez Del Castro (2010) o intervalo vai de 1994 a 2005; Tapscott (2010) acredita que a Geração Z agrega indivíduos nascidos depois do ano 1998 e Tolbize (2008) define que esses sujeitos nasceram após o ano de 1990.

Neste estudo denomina-se Geração $Z$ os indivíduos que nasceram após o ano de 1994, por abranger o intervalo mencionado por alguns dos autores apresentados anteriormente. A Geração $Z$ agrupa jovens que se desenvolveram em contato com computadores, dispositivos móveis, com a velocidade dos meios de comunicação e informação e outros recursos tecnológicos.

\footnotetext{
${ }^{1}$ Existem quatro principais gerações vivas: os Baby Boomers, a Geração X, a Geração $Y$ e a Geração Z (CERBASI; BARBOSA, 2009; TAPSCOTT, 2010).
} 
Este trabalho foi desenvolvido com o objetivo de verificar a participação da Geração $Z$ nas plataformas tecnológicas. $O$ trabalho baseia-se na perspectiva de que as gerações sociológicas (definida na próxima seção) se caracterizam pelas vivências históricas ou por transformações como culturais e tecnológicas. A revolução da informática, iniciada com o computador pessoal, parece ganhar nova conotação com o estabelecimento da internet e o surgimento de dispositivos que podem permitir novos cenários para 0 compartilhamento da informação, e a Geração Z, que cresceu com as possibilidades da tecnologia digital, parece se adaptar facilmente ao advento dessas novas possibilidades.

O contato com integrantes da Geração Z em uma escola federal de ensino médio no norte do Paraná, permitiu a observação de que os nativos digitais migram de dispositivos com certa constância, e o advento de uma nova ferramenta informacional faz com que eles abandonem a que estão utilizando e passem a trabalhar com outra, algumas vezes pode até decretar 0 "desaparecimento" da tecnologia antecessora. Para que seja possível investigar a relação entre os agentes e as ferramentas tecnológicas, que mesmo de forma interdependente possuem papéis relacionais, utilizamos a Análise de Redes Sociais (ARS) e o trabalho é complementado pela técnica de Grupo Focal (GF) por possibilitar a verificação das percepções dos integrantes da Geração Z em relação à tecnologia.

\section{GERAÇÃO Z}

Quando nos referimos às gerações sociológicas estamos nos reportando ao que tradicionalmente se considera como a separação de 20 ou 25 anos para diferenciar uma da outra. Cada geração passa por um conjunto único de episódios que demarca seu lugar na história e molda suas perspectivas. Neste trabalho, as gerações são classificadas não só pela data de nascimento, mas também pelo conjunto de vivências, princípios de vida e transformações tecnológicas que presenciaram.

$\mathrm{Na}$ sociedade atual são caracterizados quatro principais grupos sociológicos vivos: os Baby Boomers, a Geração X, a Geração Y e a Geração 
Z (CERBASI; BARBOSA, 2009; TAPSCOTT, 2010). Os Baby Boomers são sujeitos nascidos entre 46 e 64 (CERBASI; BARBOSA, 2009; TAPSCOTT, 2010; TOLBIZE, 2008); 41 e 65 (CRISTIANI, 2010); entre 51 e 64 (RODRÍGUEZ SEGURA; PELÁEZ GARCIA, 2010). Na Geração X ou Baby Bust encontram-se indivíduos que nasceram entre 1965 e 1980 (CERBASI; BARBOSA, 2009); 1965 a 1983 (RODRÍGUEZ SEGURA; PELÁEZ GARCIA, 2010); entre 1964 e 1977 (SANTOS et al., 2011); 1965 a 1976 (TAPSCOTT, 2010); 1964 e 1982 (TOLBIZE, 2008). A Geração Internet, Geração do Milênio (TAPSCOTT, 2010), é também denominada Geração Y (CERBASI; BARBOSA, 2009; TAPSCOTT, 2010). Nessa geração estão sujeitos que nasceram entre os anos 1979 e 2000 (CERBASI; BARBOSA, 2009). Para Santos et al. (2011) seus integrantes nasceram entre 1978 e 1994 e estão entrando no mercado de trabalho agora, oriundos de um período econômico de crescimento bastante favorável. Nascidos entre 1994 e 2005 (FERNANDEZ DEL CASTRO, 2010), a Geração Z é a primeira composta por nativos digitais em sentido estrito, pois chegaram ao mundo em pleno ápice do consumismo. Usam a comunicação instantânea para interações (comunidades online). Seu individualismo radical também é expresso nos ambientes virtuais em detrimento à comunicação verbal. Apostam na inteligência e tecnologia para a educação e trabalho e geralmente são impacientes por terem hábitos de ação e satisfação imediata. Participam de grandes comunidades virtuais, sem se envolver pessoalmente.

São filhos de pais separados que formaram novas famílias, as "famílias recompostas", e suas atividades cotidianas no mundo digital são muito bem estruturadas, capaz de conscientizá-los ética e socialmente. Rejeitam a educação formal, incluindo a carreira universitária, o que, junto com seus problemas de comunicação pessoal, provoca uma lacuna difícil de preencher entre as gerações anteriores e futuras, potencializando uma escassez vindoura de profissionais qualificados (FERNANDEZ DEL CASTRO, 2010). Neste estudo é investigada a participação da Geração Z nas plataformas tecnológicas. 


\section{TECNOLOGIA}

O crescimento exponencial da área de informática, do processamento e distribuição da informação, além de preconizar uma demanda por formas de tecnologias mais sofisticadas, obriga o ser humano a estar em conformidade com o uso de tecnologias emergentes, sob pena de se tornarem seres obsoletos. Os aparatos tecnológicos, que antes pareciam distantes, disponíveis apenas em centros de computação ou nas camadas mais elevadas da população, tornaram-se bens de consumo acessíveis, possibilitando a atualização dos conhecimentos.

Em conjunto com alguns dispositivos como smartphones ou tablets, as redes passam a ter um papel fundamental na evolução tecnológica. De modo primário, uma rede nada mais é do que um conjunto de "nós" interconectados, "nós" que podem ser tanto pessoas quanto equipamentos. Sociologicamente a formação de redes é uma prática antiga dos seres humanos, mas nesse "tempo de tecnologias", as redes conseguiram vida nova, transformando-se em redes de informação energizadas pela internet (CASTELLS, 2003).

O uso de tecnologias e dos ambientes digitais é encarado como um processo natural da sociedade atual, a qual seres humanos e instituições são constantemente pressionados a encontrar meios que permitam a utilização, produção e organização dos diferentes tipos de informação, serviços e produtos, bem como a interação social por meio dos dispositivos eletrônicos. "Cada vez mais as tecnologias digitais permeiam as atividades humanas, mas isso também demanda que os indivíduos desenvolvam consistentes habilidades técnicas, cognitivas e sociais" (BORGES et al., 2012, p.2). Indivíduos que não se adaptam à cultura digital correm até o risco de serem excluídos dos grupos sociais. As tecnologias digitais propiciam novas possiblidades por estarem presentes em vários segmentos da sociedade, e quando utilizadas de forma sensata proporcionam novos convívios sociais e vasto acesso a novas informações.

A tecnologia evoluiu da simples busca de informação para a atual web colaborativa, em que os indivíduos também criam os conteúdos, assim, a interação social parece apresentar-se como decisiva na comunicação. Para 
Tomaél (2005, p.40) "[...] as escolhas de comunicação incidem, sobretudo, entre as interações programadas e as não-programadas. [...] O uso da mídia para a comunicação é determinado tanto socialmente quanto tecnologicamente e normativamente".

As inovações tecnológicas pautadas pela crescente evolução eletrônica e avanços digitais mudaram e moldaram processos culturais em diversas áreas. Não só na esfera científica, mas os elementos humanos desse processo sofreram e continuam sofrendo interferências constantes dos aparatos tecnológicos nos mais variados contextos sociais.

\section{METODOLOGIA}

A metodologia empregada para averiguar o objetivo, na primeira fase, foi a ARS, a análise dos dados dessa fase foi feita pelo UCINET e pelo NETDRAW, que possibilitaram a configuração da rede e a apresentação de medidas que especificam os padrões dos relacionamentos (MARTELETO; TOMAÉL, 2005).

A pesquisa foi desenvolvida em uma escola federal de ensino médio no norte do Paraná, e a comunidade para o estudo foi formada por alunos do $3^{\circ} \mathrm{e}$ $4^{\circ}$ anos do curso técnico de informática da instituição, os quais agrupam indivíduos nascidos após o ano 1994, pertencentes à Geração Z. Participaram 23 alunos do $3^{\circ}$ ano, 11 eram do sexo masculino e 12 do sexo masculino. Do $4^{\circ}$ ano, 17 alunos integraram o estudo, 10 do sexo masculino e 7 do sexo feminino, portanto, as ponderações estão baseadas em duas redes: a rede social do $3^{\circ}$ ano e a rede social do $4^{\circ}$ ano. Os processos para a realização da pesquisa respeitaram os padrões éticos da investigação científica, obteve-se a permissão do diretor da instituição para o estudo empírico e o aceite dos pais dos estudantes pelo Termo de Consentimento Livre e Esclarecido (TCLE).

O instrumento inicial foi o questionário ${ }^{2}$, aplicado em maio de $2015 \mathrm{em}$ um dos laboratórios de informática da instituição. Os atores para o GF foram

${ }^{2}$ O questionário foi elaborado e aplicado utilizando a ferramenta Google Docs. 
selecionados após os resultados da primeira fase e a reunião se deu em agosto de 2015. O encontro foi gravado em forma de vídeo por um integrante auxiliar para posterior transcrição. Nessa etapa a análise dos dados foi feita por temas e categorias, fundamentada na análise de conteúdo.

\section{ANÁLISE DE REDES SOCIAIS}

Neste trabalho, os atores nas figuras são identificados pelos quadrados "azuis" ou "rosa", além das siglas das iniciais de seus nomes. As ligações ou vínculos do compartilhamento de informação entre os nós podem ser assimétricos (A indica $B$ ), a linha parte de um ator em direção a outro e mostra uma relação sem reciprocidade (linhas pretas); e simétricos ( $A$ indica $B$ e $B$ indica $A$ ), relação recíproca com linhas (vermelhas) bidirecionais (HANNEMAN, 2001).

Quanto ao aspecto de como os processos de comunicação acontecem, existem duas categorias, classificados em processos assíncronos ou síncronos, e nesse caso, refere-se à simultaneidade de participação dos atores nos processos comunicacionais. Assíncronos são representados pelos aparatos tecnológicos, simbolizados no trabalho por plataformas como Facebook, WhatsApp e e-mail, tecnologias em que a comunicação pode ocorrer inicialmente com apenas uma das partes, sem que o receptor participe instantaneamente do processo. Síncronos são representados pelos contatos pessoais, agrupados nesta pesquisa em telefone e pessoalmente, métodos em que há participação simultânea dos atores nos processos de comunicação.

Conforme as Figuras 1 e 2, os resultados parecem confirmar "em partes" as conjecturas dos autores em relação à Geração $Z$ sobre os meios de comunicação. A análise mostra um número significativo de participantes da pesquisa que, mesmo indicando comunicar-se por meio de aparatos tecnológicos (processo assíncrono), também utiliza o contato pessoal (processo síncrono) como meio de comunicação. Por isso a utilização do termo "em partes", porque embora o mundo digital faça parte do cotidiano desses alunos, os resultados mostram que os atores das duas redes mantêm o hábito de se comunicarem pessoalmente. 
Figura 1 - Meios de comunicação $-3^{\circ}$ ano

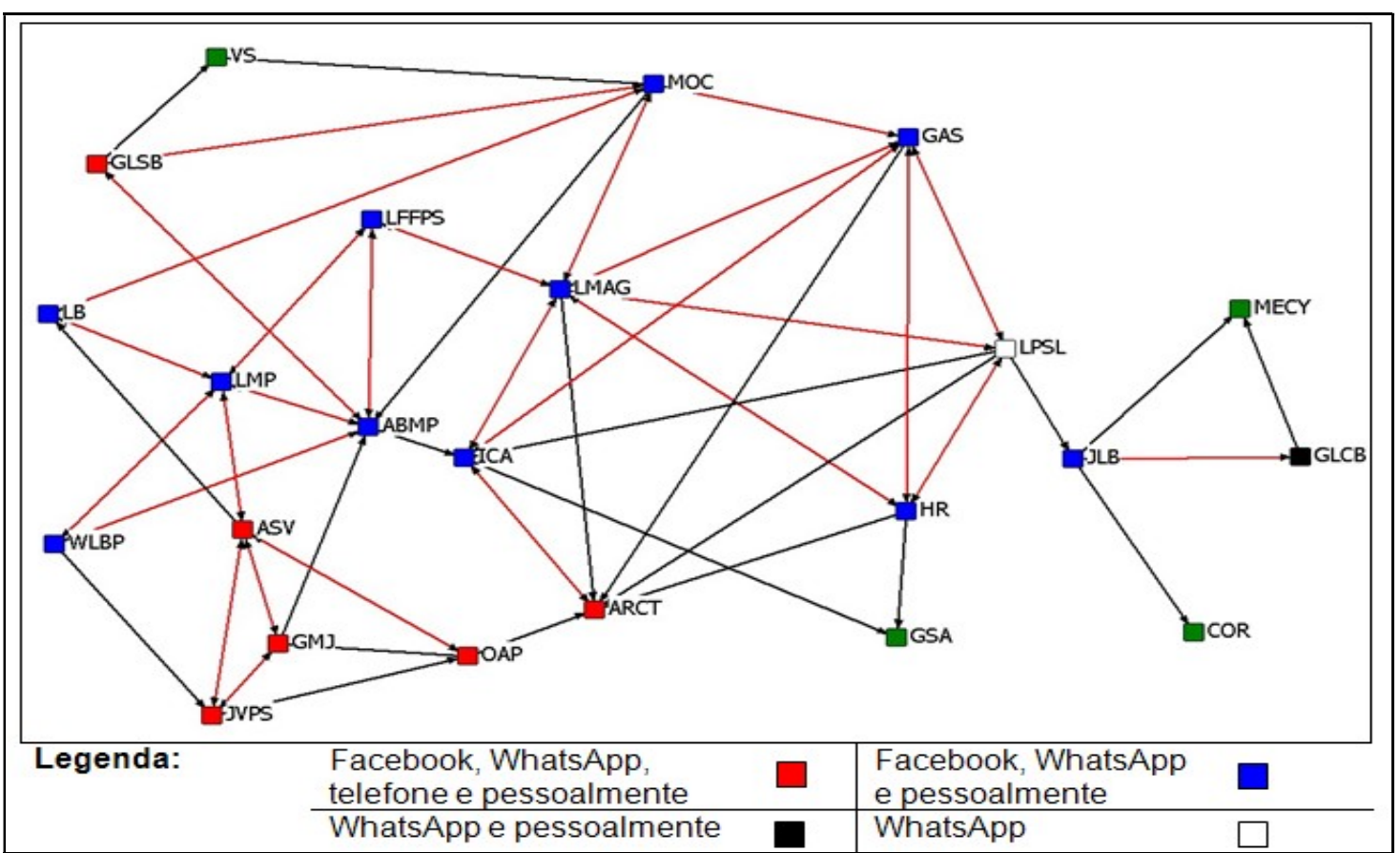

Fonte: dados da pesquisa

$\mathrm{Na}$ rede mostrada na Figura 1 apenas 0 ator LPSL indicou exclusivamente como o meio mais utilizado para a comunicação uma das tecnologias digitais, o WhatsApp. Na rede apresentada na Figura 2, em comparação com a Figura 1, a situação é recorrente, somente um ator, CAVF, utiliza-se unicamente da mesma tecnologia como principal meio comunicação com seus pares. Portanto, nas duas redes, apenas dois atores utilizam-se exclusivamente de meios digitais (processo assíncrono) como forma de comunicação.

No $3^{\circ}$ ano, os meios de comunicação utilizados com maior ocorrência são o Facebook, WhatsApp e pessoalmente. Onze atores indicaram esses meios como preferencial: ABMP, GAS, HR, ICA, JLB, LB, LMP, LMAG, LFFPS, MOC e WLBP. A segunda maior ocorrência de indicações são o Facebook, WhatsApp, telefone e pessoalmente; seis nós preferem esses meios para partilhar informação: ASV, ARCT, GMJ, GLSB, JVPS e OAP. O ator GLCB faz uso do WhatsApp, mas também se comunica pessoalmente. Os atores GSA, COR, MECY e VS são indivíduos que aparecem na rede por terem sido lembrados pelos colegas, mas não fizeram indicações por não estarem presentes no dia do questionário. 
Figura 2 - Meios de comunicação $-4^{\circ}$ ano

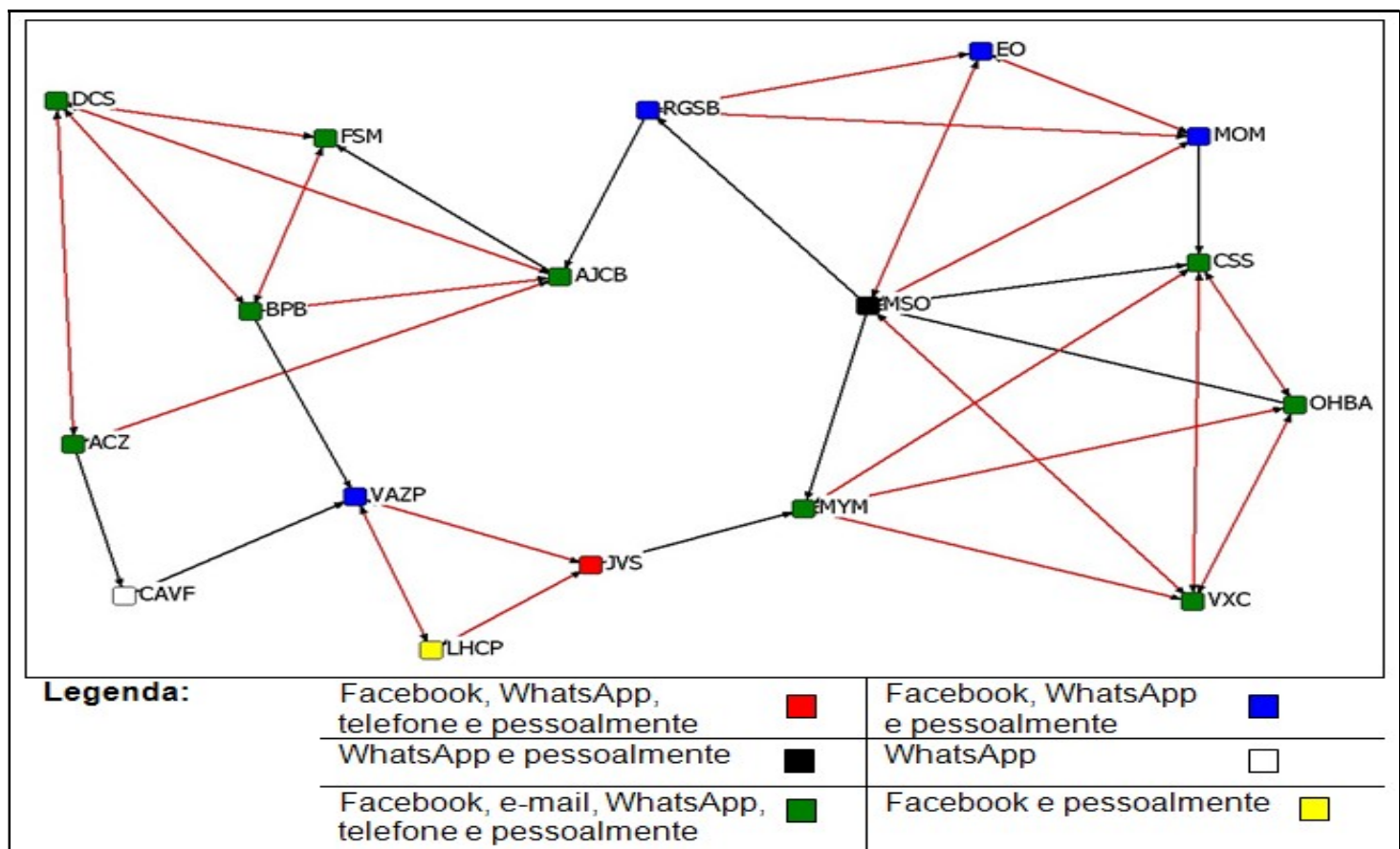

Fonte: dados da pesquisa

Os resultados na rede do $4^{\circ}$ ano (Figura 2) demonstram que nove atores: ACZ, AJCB, BPB, CSS, DCS, FSM, MYM, OHBA e VXC fazem uso do Facebook, e-mail, WhatsApp, telefone e pessoalmente para se comunicarem com seus pares. Os resultados também exprimem que os atores: EO, MOM, RGSB, VAZP compartilham informação na rede utilizando o Facebook, WhatsApp e pessoalmente. O ator JVS comunica-se por meio do Facebook, WhatsApp, telefone e pessoalmente. O ator MSO compartilha informação pelo WhatsApp e pessoalmente, e o ator LHCP, na maioria das vezes, interage com a rede no Facebook e pessoalmente.

A análise das duas redes confirma o pensamento de Garton, Haythornthwaite e Wellman (1997) sobre como as relações de A e B ou A e C são afetadas pelo vínculo de C e B. Podemos considerar que os integrantes das redes apresentam padrões de conduta parecidos em relação aos meios de comunicação, e podem ter sido influenciados pelos vínculos com seus pares no que tange à formação de redes em ambientes virtuais, dada a notoriedade atribuída às plataformas tecnológicas.

Se por um lado nas redes estudadas existem muitas interações no mundo digital, por outro, há um número muito representativo de contatos 
pessoais como meio de comunicação, por isso, o tipo de formação e espaço de encontro das redes estudadas pode explicar o alto índice de indicações de comunicações síncronas dentro das turmas. A grande quantidade de ocorrência de comunicações por contato pessoal nessas redes parece fenômenos sociais que acontecem por normas impostas pela sociedade, neste caso, a organização das escolas com turmas agrupadas em sala (REQUENA SANTOS, 1989).

\section{6 ÓTICA DA GERAÇÃO Z SOBRE A TECNOLOGIA}

Quanto a estarem sempre conectados, os participantes do GF entendem que as facilidades tecnológicas os deixam em contato constante com outras pessoas, a necessidade de ficar online grande parte do tempo decorre da sensação de proximidade com indivíduos do círculo de amizade. O sentimento da presença de alguém a todo o momento é classificado como fator preponderante e o hábito do contato virtual possibilita o acesso às informações.

$O$ desejo de se manterem online nasce de uma urgência em inteirar-se de tudo o que acontece de maneira instantânea e da existência do sentimento de solidão se lhes fossem tirados os dispositivos móveis e o acesso à internet. Para os pesquisados, o conjunto tecnológico que permite a rápida comunicação e o contato com várias pessoas é visto simplesmente como uma ferramenta, a qual Ihes permite a comunicação com indivíduos presentes em qualquer lugar.

O fato de permanecerem conectados à tecnologia não lhes parece imprescindível, mas se for necessário realizar alguma ação em que há possibilidade de aproveitamento dos recursos tecnológicos, não encontram motivos para não utilizar. A tecnologia é o recurso que provê facilidade para diversas finalidades. "Não é uma necessidade, o meio mais viável que nós temos hoje em dia para compartilhar qualquer tipo de informação é por meio 
dessas plataformas. Então eu não vejo o porquê de usar outros meios pra fazer isso" (partic. VAZP) .

Utilizar a tecnologia virou um hábito entre os membros presentes no GF desta pesquisa. Não é que a tecnologia seja essencial em tudo o que se faz, mas parece inegável a noção de dificuldade em ficar sem ela, pautada principalmente nas oportunidades que a tecnologia pode proporcionar. Os participantes consideram interessante o poder de alcance e mobilidade propiciado tanto para quem envia quanto para quem recebe informações, entretanto, julgam passar bastante tempo em contato com os amigos no mundo digital e acabam deixando de lado a convivência com pessoas com as quais moram.

A investigação mostrou que os participantes se preocupam com o distanciamento e a falta de contato pessoal. Acreditam que as crianças das gerações futuras não terão o hábito de sair de casa para se encontrarem com os amigos. Há o temor de que cada vez mais as pessoas ficarão nas casas se relacionando no mundo digital e, conforme a tecnologia evolua, imaginam que a falta de convívio social tende a piorar.

Para os participantes da pesquisa, os indivíduos que agora são considerados crianças, manifestam interesse no entretenimento baseado na tecnologia digital, e por já estarem acostumados às conexões do mundo virtual, em grande parte do tempo, parecem não sentir a necessidade da presença física para as atividades de lazer, sinalizados por Fernandez Del Castro (2010) como o individualismo radical com participações em comunidades virtuais sem envolvimento pessoal.

Acho que as pessoas se afastaram por uma questão de informação. Cresceu tanto o fluxo de informação na internet que diminuiu o contato pessoal. Por exemplo, se eu for fazer alguma coisa, eu leio na internet e já pego, não preciso procurar alguém pra perguntar ou ir a um lugar como biblioteca. Então as pessoas acabam sendo mais desprendidas umas das outras. Se quero aprender algo eu não preciso ir a um

\footnotetext{
${ }^{3}$ Os participantes do Grupo de Foco foram identificados por códigos para manter o anonimato na pesquisa.
}

Inf. Inf., Londrina, v. 22, n. 2, p. 371 - 388, maio/ago., 2017. http:www.uel.br/revistas/informacao/ 
especialista nisso, eu procuro na internet e me viro, vou na tentativa e erro. Acaba sendo mais fácil isso (partic. MYM).

O mundo digital possibilita aos integrantes da Geração $Z$ o acesso a um vasto universo de informações e oportuniza o esclarecimento sobre assuntos diversos. Devido a isso, a comunicação pessoal parece ficar em segundo plano, pois eles supõem que a quantidade de informação na internet é tão grande que encontrarão nesse universo tudo que precisam, apostam na inteligência e tecnologia para aprendizagem e desenvolvimento de atividades (FERNADEZ DEL CASTRO, 2010).

Constatou-se que ao contrário de algumas argumentações (CERBASI; BARBOSA, 2009; JEANNERET, 2005; TAPSCOTT, 2010), os participantes do GF entendem que não nasceram imersos em bits, avaliam que os indivíduos que nasceram depois deles é que já chegaram ao mundo em contato direto com a tecnologia digital. "Nós somos um pouquinho antes da Geração Z então, quem nasce agora está imerso nos ambientes virtuais e nos dispositivos móveis e por isso junto com os bits, nós não" (partic. HR). As tecnologias digitais apareceram no decorrer de suas vidas, o contato com o mundo tecnológico se deu gradativamente e foram se adaptando aos novos conceitos de comunicação e acesso à informação.

Essa geração que está agora que é a Geração Z, porque quando eu era criança, eu não tinha essa relação tão forte com a tecnologia. Hoje eu vejo meu primo que só tem dois anos, já sabe mexer em todos os equipamentos, tablet, celular, computador, isso comigo não existia. Eu fui conhecer isso quando eu tinha uns sete ou oito anos. Então eu acho que a Geração Z é essa que nasceu agora sim (partic. LMAG).

Nós viemos depois do 'boom' da internet, dos fóruns, mas nós não tínhamos acesso. A tecnologia era muito cara e a gente então tinha que sair para brincar. Hoje em dia percebemos que uma criança sabe ligar um computador, mas não sabe andar de bicicleta, pelo fato da tecnologia ter evoluído. Hoje em dia muita gente mora em apartamento, as crianças nascem e ficam sozinhas, e vão para o celular, ou até mesmo os pais dão celular na mão pra criança não ficar fazendo birra. Então a gente nasceu nos bits, mas essas crianças nasceram, estão crescendo e vão morrer neles, a gente ficou meio fora (partic. $M O C)$. 
Cabe-nos uma ressalva de que a categorização das gerações (CERBASI; BARBOSA, 2009; JEANNERET, 2005; TAPSCOTT, 2010) se baseou em uma realidade encontrada em países desenvolvidos. Talvez a realidade brasileira que se apresenta seja distinta da que os autores fundamentaram em suas pesquisas, assim como em outros países também seria, pois cada nação tem sua peculiaridade. A mesma situação pode ocorrer na cidade em que foi feita esta pesquisa. $O$ desenvolvimento tecnológico e social em um município pequeno do interior paranaense, provavelmente não é similar às grandes metrópoles como São Paulo ou Rio de Janeiro, por isso as particularidades apresentadas, aqui, dizem respeito aos cenários em que a pesquisa se desenvolveu.

Um dado importante também percebido na pesquisa em relação ao contato com as tecnologias foi a importância que a Geração $Z$ dá aos aparatos tecnológicos. Quase a totalidade dos participantes argumentou que enquanto não se tem a tecnologia, ela não parece tão importante, porém depois que se tem o primeiro aparelho é difícil se acostumar a ficar sem, mas não apenas pelo dispositivo e sim pela ausência de comunicação e acesso às informações que a falta do aparelho pode causar. $\mathrm{Na}$ concepção dos pesquisados, ficar de fora dos acontecimentos e sem receber as informações pode lhes acarretar prejuízos. As informações são compartilhadas nas redes sociais, o compartilhamento é constante e, para ficar por dentro dos acontecimentos, o sujeito precisa estar conectado.

\section{CONSIDERAÇÕES FINAIS}

Inicialmente, a análise das contribuições dos alunos no GF, propiciou a percepção de que os integrantes da Geração $Z$ aqui pesquisados acham difícil entender como as gerações antecessoras conseguiam viver sem alguns dispositivos tecnológicos presentes em seu cotidiano como os smartphones. Eles não conseguem sequer imaginar como aconteciam as comunicações antes do mundo digital em termos de facilidade e agilidade de acesso à informação. Entretanto, os dispositivos móveis não são encarados por eles 
como extensão do corpo (JEANNERET, 2005), algo que não se consiga viver sem.

Sua utilização é vista como uma atitude costumeira, é como se a tecnologia fizesse parte da rotina, estar online é totalmente natural e para eles não há nada de extraordinário nisso. A rapidez para os participantes do GF é o ritmo habitual. As informações geralmente são compartilhadas no mesmo instante em que acontecem e a tecnologia é corriqueira, fazendo parte do cotidiano.

Nas gerações anteriores as pessoas pareciam mais próximas. Com a crescente necessidade de se adquirir bens diante do mundo capitalista, a vida aparentemente se tornou muito mais atribulada do que outrora, abrindo espaço para os contatos nas redes sociais digitais. O convívio pessoal percebido há tempos, supostamente foi se desfazendo pelas preocupações constantes dos afazeres diários da sociedade. Mesmo que na contramão, o crescimento populacional também parece contribuir para que os indivíduos se afastem. Por haver mais contato pessoal entre os integrantes das gerações predecessoras, tem-se a sensação de que havia mais humanização nos relacionamentos.

As tecnologias digitais no Brasil ainda não estavam num estágio avançado quando os integrantes da Geração $Z$ eram crianças, por isso eles acreditam que na infância mantinham hábitos considerados pertinentes ao momento, como, por exemplo, se juntarem para jogar futebol na rua ou empinar "pipa". Com a evolução dos meios de comunicação e dos aparatos tecnológicos, os participantes da pesquisa acreditam que as "novas gerações" provavelmente irão se distanciar dos encontros pessoais para a diversão.

Diante disso, uma constatação deste trabalho é de que o acesso à tecnologia para os integrantes da Geração $Z$ não era tão fácil, os preços elevados não permitiam que grande parte da população obtivesse aparelhos digitais sempre que quisesse. Aparentemente, as crianças de hoje têm possibilidade de adquirir os smartphones de forma menos complicada, pois segundo Fernandez Del Castro (2010), a Geração Z chegou ao mundo em pleno pico da era do consumo.

O trabalho aponta para mudanças regulares das atuações dos integrantes da Geração Z em diferentes dispositivos tecnológicos. É importante 
identificar em qual plataforma eles estão presentes, já que para os pesquisados a mudança pode ocorrer a qualquer momento, e manterem-se conectados ao mundo digital é corriqueiro e habitual. Dessa forma, novos estudos podem verificar o entendimento de outra geração sociológica sobre a tecnologia e tentar traçar um paralelo entre os dois grupos, de modo a entender como os indivíduos das diferentes gerações atuam nos dispositivos tecnológicos para compartilhar informação.

\section{REFERÊNCIAS}

BORGES, Jussara et al. Competências infocomunicacionais: um conceito em desenvolvimento. Tendências da Pesquisa Brasileira em Ciência da Informação, Brasília, v. 5, n. 1, 2012. Disponível em: $<$ http://inseer.ibict.br/ancib/index.php/tpbci/article/view/67/109>. Acesso em: 20 abr. 2014.

CASTELLS, Manuel. A galáxia da internet: reflexões sobre a Internet, negócios e a sociedade. Rio de Janeiro: Jorge Zahar Ed., 2003.

CERBASI, Gustavo; BARBOSA, Christian. Mais tempo, mais dinheiro. Rio de Janeiro: Thomas Nelson Brasil, 2009.

CRISTIANI, Alvaro. La generación Einstein. Revista de Antiguos Alumnos del IEEM, Montevideo, v. 13, n. 2, p. 57-61, abr. 2010. Disponível em: $<$ https://dialnet.unirioja.es/servlet/articulo?codigo $=3233558>$. Acesso em: 07 abr. 2015.

FERNANDEZ DEL CASTRO, José Ignacio. Juventud:¿ser quien es? Ábaco: Revista de Cultura y Ciencias Sociales, Gijón, v. 4, n. 66, p. 21-67, segunda época, 2010. Disponível em:

$<$ http://www.revistasculturales.com/xrevistas/PDF/72/1393.pdf>. Acesso em: 18 abr. 2015.

GARTON, Laura; HAYTHORNTHWAITE, Caroline; WELLMAN, Barry. Studying online social networks. JMC - Journal of Computer-Mediated Communication, v.3, n.1, Jun. 1997. Disponível em:

<http://onlinelibrary.wiley.com/doi/10.1111/j.1083-6101.1997.tb00062.x/full>. Acesso em: 25 abr. 2015. 
HANNEMAN, Robert. Introduction to social network methods. 2001. Disponível em: < http://faculty.ucr.edu/ hanneman/nettext/Introduction to Social Network Meth ods.pdf>. Acesso em: $10 \mathrm{dez} 2014$.

JEANNERET, Yves. Dispositif. In: La societé de i'nformation: glossaire critique. Paris: La Documentation Française, 2005. p. 50-51.

MARTELETO, Regina Maria; TOMAÉL, Maria Inês. A metodologia de Análise de Redes Sociais (ARS). In: VALENTIM, Marta Lígia P. (Org.). Métodos qualitativos de pesquisa em ciência da informação. São Paulo: Polis, 2005. p. 81-99.

PRENSKY, Marc. Digital natives, digital immigrants. MCB University Press, 2001. Disponível em: <https://edorigami.wikispaces.com/file/view/PRENSKY++DIGITAL+NATIVES+AND+IMMIGRANTS+1.PDF>. Acesso em: 15 jun. 2014.

REQUENA SANTOS, Félix. El concepto de red social. Revista Española de Investigaciones Sociológicas, Madrid, n.48, p. 137-152, 1989. Disponível em <http://www.reis.cis.es/REIS/PDF/REIS 048 08.pdf>. Acesso em: $17 \mathrm{dez}$. 2014.

RODRÍGUEZ SEGURA, Enrique; PELÁEZ GARCÍA, Miguel Angel. La convivencia de diferentes generaciones en la empresa: compatibilización y liderazgo integral. In: International Conference on Industrial Engineering and Industrial Management, 4., 2010, Donostia-San Sebastián. Anais eletrônicos..., 2010. p. 160-170. Disponível em:

<http://adingor.es/congresos/web/uploads/cio/cio2010/BUSINESS ADMINISTR ATION//160-170.pdf>. Acesso em: 15 abr. 2015.

SANTOS, Cristiane Ferreira et al. O processo evolutivo entre as gerações $X, Y$ e baby boomers. In: SEMINÁRIOS EM ADMINISTRAÇÃO - SEMEAD, 14., São Paulo. Anais eletrônicos... São Paulo: FEA-USP, 2011. Disponível em: $<$ https://originaconteudo.com.br/arquivos/Artigo-geracoes-X-Y-e-Babyboomers.pdf>. Acesso em: 01 abr. 2015.

TAPSCOTT, Don. A hora da geração digital: como os jovens que cresceram usando a internet estão mudando tudo, das empresas aos governos. Rio de Janeiro: Agir Negócios, 2010.

TOLBIZE, Anick. Generational diferences in the workplace. Minnesota: research and training center on community living, aug. 2008. Disponível em: <http://rtc.umn.edu/docs/2 18 Gen diff workplace.pdf>. Acesso em: 01 abr. 2015. 
TOMAÉL, Maria Inês. Rede de conhecimento: o compartilhamento da informação e do conhecimento em consórcio de exportação do setor moveleiro. 292 f. Tese (Doutorado em Ciência da Informação) - Programa de PósGraduação em Ciência da Informação da Universidade Federal de Minas Gerais, Belo Horizonte. 2005.

\title{
Title
}

Generation z and technological platforms

\begin{abstract}
:
Introduction: The exponential growth of information technology, information processing and distribution makes it possible for members of Generation Z to access a vast universe of information on various subjects. Objective: To verify the participation of Generation Z in the technological platforms carried out with students of the 3rd and 4th years of a federal high school in the northern of Paraná.

Methodology: Social Network Analysis (SNA), which made it possible to verify the level of interaction and sharing of information through technological devices, and the Focus Group technique (GF), made by themes and categories, based on content analysis. Results: The act of staying online favors the feeling of closeness with other individuals, a factor considered important in access to information and in the possibility of immediate updating of events. By maintaining the habit of using technology, Generation $Z$ is accustomed to constant contacts, quick and easy access to information, and so it would be hard to get rid of platforms like smartphones. Conclusions: Conduct in front of technology platforms is seen as a day-to-day action rather than as an essential habit, even though they identify that a lack of technology can deprive them of opportunities. Although used to the technological processes of communication and information, the group researched here does not consider that it was born along with the technology, but they were adapting to it.
\end{abstract}

Keywords: Information Sharing. Mobile device. Analysis of Social Networks. Social networks.

\section{Titulo}

La generación z y las plataformas tecnológicas

\section{Resumen:}

Introducción: El crecimiento exponencial del área de informática, del procesamiento y distribución de la información posibilita a los integrantes de la Generación Z el acceso a un vasto universo de informaciones sobre diversos temas. Objetivo: Verificar la participación de la Generación Z en las plataformas tecnológicas, realizado con alumnos del $3^{\circ}$ y $4^{\circ}$ años de una escuela federal de enseñanza media en el norte de Paraná. Metodología: Análisis de Redes Sociales (ARS), que posibilitó verificar el nivel de interacción y compartir información a través de dispositivos tecnológicos, y la técnica de Grupo Focal (GF), hecha por temas y categorías, basada en el análisis de contenido. Resultados: El acto de permanecer en línea favorece la sensación de proximidad con otros individuos, factor considerado importante en el acceso a la información y en la posibilidad de actualización inmediata de los acontecimientos. Por

Inf. Inf., Londrina, v. 22, n. 2, p. 371 - 388, maio/ago., 2017. http:www.uel.br/revistas/informacao/ 
mantener el hábito de utilización de tecnología, la Generación Z está acostumbrada a contactos constantes, acceso fácil y rápido a la información, y por eso sentiría dificultad en deshacerse de plataformas como smartphones. Conclusiones: Las conductas frente a las plataformas tecnológicas son vistas más como acciones cotidianas que como hábitos esenciales, aunque identifiquen que la falta de tecnología puede privarles de oportunidades. Incluso habituados a los procesos tecnológicos de comunicación e información, el grupo aquí investigado no considera que nació junto con la tecnología, pero se fueron adaptando a ella.

Palabras clave: Compartir información. Dispositivo móvil. Análisis de Redes Sociales. Redes sociales.

Recebido: 30.08 .2017

Aceito: 30.09 .2017 